\title{
The Effect of a Social Enrichment Programme on the Behaviour of Dogs from a Private Shelter
}

\author{
Silvana POPESCU ${ }^{1}$, Cristin BORDA ${ }^{1}$, Cristina EL MAHDY ${ }^{2}$, Eva-Andrea LAZAR ${ }^{1}$, Anamaria BLAGA \\ PETREAN $^{1}$, Ioana-Diana CÂMPEAN ${ }^{1}$, Marina SPINU ${ }^{1}$ \\ ${ }^{1}$ Faculty of Veterinary Medicine, University of Agricultural Sciences and Veterinary Medicine, Cluj-Napoca, \\ Romania \\ ${ }^{2}$ Faculty of Animal Science and Biotechnologies University of Agricultural Sciences and Veterinary \\ Medicine, Cluj-Napoca, Romania \\ *corresponding author: cristina.hegedus@usamvcluj.ro
}

Bulletin UASVM Veterinary Medicine 75(2)/2018

Print ISSN 1843-5270; Electronic ISSN 1843-5378

doi:10.15835/buasvmcn-vm:2018.0032

\begin{abstract}
:
The aim of this study was the behavior assessment of dogs housed in a private shelter, before and after implementing an intensive social enrichment programme. Using an assessment protocol of provoked and unprovoked behavior, a range of behavioral indicators was recorded in 20 dogs housed for more than two years in the shelter. The data collected was used for computing a quality of life score (QL). After the implementation of the social enrichment programme, 75\% of the studied dogs received higher QL scores compared with the initial assessment. At that stage, also a slight increasing in the proportion of the dogs' positive indicators was seen. No significant difference was recorded when compared the results obtained by the two assessors. The higher QL scores obtained after the enrichment programme prove that such a programme has positive effects on the behavior and on the life quality of shelter dogs.
\end{abstract}

Keywords: dog behaviour, quality of life score, social enrichment

\section{Introduction}

In the light of recent research, the literature recognizes the importance of socialization programmes in sheltered dogs. The implementation of these programmes can reduce the negative effects of sheltering by improving their life quality and decreasing unwanted behaviors and it can increase the chances for adoption of these animals. The behavioral repertoire of the individual subjected to such programmes is improved by encouraging the expression of species specific manifestations, by preventing, reducing or eliminating the abnormal behavioral patterns such as stereotypes, and also by increasing the ability of the animal to cope with new situations (Wells, 2004). Those dogs that have a better physical and psychological condition are easier to care for and give for adoption and they have a better welfare (Moesta et al., 2015).

Among the most frequently used methods that had good results in the human-dog interaction are petting, grooming, playing (using toys) or walking the animals outside the pen (Kiddie and Collins, 2014; Normando et al., 2009).

Previous research show, also, that the time spent in the shelter influences the dogs' behavior (Wells et al., 2002; Wells, 2004). When they are sheltered for longer times, these programmes can provide appropriate stimuli to encourage learning and to prevent boring.

The aim of this study was the behavioral assessment of the dogs in a private shelter before and after implementing an intensive socialization programme. The hypothesis of the research was 
that an intensive socialization programme implemented for the dogs sheltered for a long time can lead to the improvement of the life quality and the behavior of these animals showed not only toward the person who does the socialization but also toward foreign assessors.

\section{Materials and methods}

The study was performed in a private dog shelter in Romania owned by an animal protection association (non-governmental organization). The animals selected (a total number of 20 dogs) were sheltered for more than two years and none had any documented health problem at the start of the study. There were also excluded the old animals and those showing aggressiveness toward the assessors.

The behavior of the selected animals was assessed by direct observation at the beginning of the study (assessment I) and after finishing the socialization period (assessment II). The assessment was performed based on a number of 43 behavioral indicators that indicate negative and positive emotional states (both provoked and unprovoked behavioral reactions). The behavioral characteristics were recorded using a binary system $1 / 0$, where 1 has meant the occurrence of a given behavior and 0 has meant its absence, in a given time period, during the assessment that was done. The ethogramme used, proposed first by Kiddie and Collins (2014), was adapted to the conditions in the shelter. Thus, the characteristics not shown by the dogs, both because the design of the shelter and because of other objective reasons, were excluded from the original ethogramme.

The first assessment of the dogs' behavior was made by only one assessor (A1), and the second assessment was performed by two assessors of which one was already familiar for the dogs (A1) and the second one was unknown (A2). Both the assessors were trained to use the assessment protocol in a previous study performed in 10 dogs kept in similar conditions with those included in the present study. The training of the assessors was made until an intra- and inter-assessor agreement of $89 \%$ was achieved.

Both the initial assessment (before the beginning of the socialization programme) and the final one were performed in similar conditions.

The intensive socialization programme was carried on during eight weeks and the assessor
A1 did it. In the first three weeks, the programme was performed in two days per week, and in the following five weeks in four days per week. This programme was done in the morning, between 8 a.m. and 11 a.m. and it involved direct human interaction with the animals, during seven minutes per animal (three minutes of petting and four minutes of grooming using a brush).

The results of the ethogramme were used to calculate a Life Quality score (LQ score) according to the method proposed by Kiddie and Collins (2014).

The data obtained were statistically processed using the SPSS programme, version 17. For the comparison of results, the Mann-Whitney test was used. The differences were considered significant if $\mathrm{P}<0.05$.

\section{Results and Discussion}

The LQ scores that were obtained in the two assessments are presented in figure 1. During the first assessment (performed before applying the socialization programme) a mean LQ score of 0.17 was obtained, ranging between -0.3 and 0.45 . The analysis of the results showed that $60 \%$ of the assessed dogs had higher LQ scores than the mean value. Six animals (D4, D9, D10, D13, D15 and D20) had negative scores.

The main score obtained by A1 in the final assessment was 0.2875 . This value represents an increase with 0.1175 of the score obtained by the same assessor in the initial assessment, the difference having no statistical significance $(P>0.05)$. This increase sustains the first part of the hypothesis, that a behavioral enrichment programme can have a positive influence on the life quality of animals kept in shelters and improves the behavior displayed toward a familiar assessor.

Out of the 20 dogs that were included in the study, an increase of the LQ score was recorded in $15(75 \%)$ between the two assessments. Only one animal (D9) had a negative LQ score at the final assessment, thus, between the two assessments performed by A1, the negative LQ scores decreased by $25 \%$. The mean score $(0.477)$ obtained by Kiddie and Collins (2015) in England for dogs sheltered for a long time, subjected to a socialization programme during six days is higher than the mean score obtained in our study by A1 after performing the socialization programme. Yet, the same authors (Kiddie and Collins, 2014) 


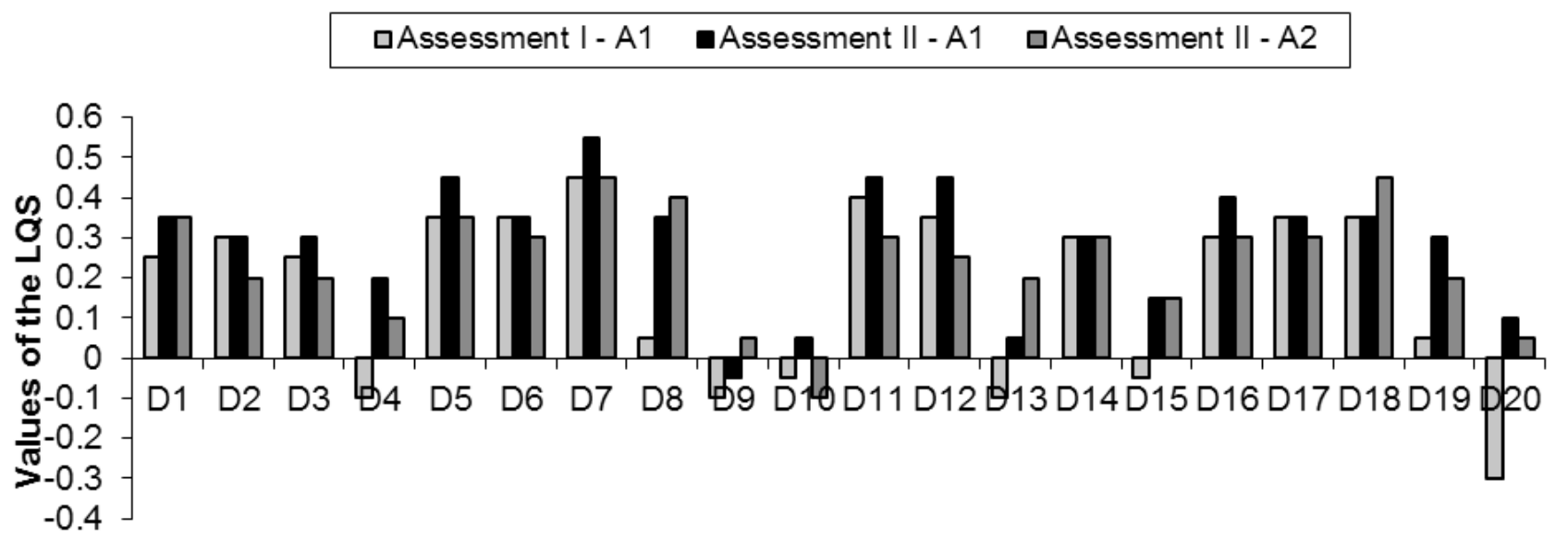

Number of dogs

LQS = Life Quality Score, A1 = assessor 1, A2 = assessor 2

Figure 1. The LQ scores obtained by the two assessors in the two assessments

suggest that the LQ score was developed as an indicator meant to monitor the life quality of the animals over time. Thus, it can be considered that a comparison between the two groups of animals in different countries, kept in different conditions is not an appropriate use for the LQ score, even if the authors of the original study use it to compare the mean scores obtained in several different studied groups of dogs. The lower scores obtained in our study could indicate the presence of chronic stress in the dogs or it could be the expression of possible traumas experienced by the animal before entering in the shelter. The dogs in a shelter can be exposed to chronic stress, because several stress factors such as social isolation, changes of the environment, excessive noises, physical restrictions (Hennessy et al., 1997; Tuber et al., 1999). In some situations, the dogs can be housed in precarious conditions, overcrowded boxes and they can have limited contact with humans (Barrera et al., 2008). In addition, for some dogs it is possible to be exposed to several traumatic situations, abuse and neglect (De Palma et al., 2005).

In that shelter where the present study was performed, the housing conditions were adequate and in conformity with the legal regulations in force. In addition, the boxes were not overcrowded. For example, in the box where six animals were housed, the surface of the kennel was six meters long and eight meters wide, resulting 6 $\mathrm{m}^{2}$ surface per animal. In these conditions, the conclusion, which can be drawn, is that insufficient socialization for prolonged periods of time, before starting the intensive socialization programme, could have been one of the causes for the lower LQ scores obtained. Even if an increase of the LQ score was noted between the two assessments performed by $\mathrm{A} 1$, this is not enough to align the obtained LQ scores to the level recorded by Kiddie and Collins $(2014,2015)$. Continuing of the socialization programme after finishing this study could lead to a continuous improving of the LQ score.

There were no statistically significant differences $(\mathrm{P}>0.05)$ between the two assessors for the LQ score. The mean LQ score recorded by the second assessor (A2) was 0.24 , namely it was lower with 0.475 than that obtained by $\mathrm{A} 1$ in the final assessment. In the assessment performed by $\mathrm{A} 2$, half $(50 \%)$ of the assessed animals had higher scores than the mean value. The maximum value for the LQ score obtained by the A2 was 0.45, recorded for D7 and D18, and the minimum of -0.1 were obtained for D10 (Figure 1). Only one animal had negative score. The values obtained by A2 for the LQ score seem to sustain the hypothesis according to which the effects of an intensive socialization programme lead to improvements in the dogs' behavior both toward the familiar assessor and toward an unknown one.

Unfortunately, the dogs kept in some shelters experience low levels of human interaction, despite the proofs that such interactions have a 


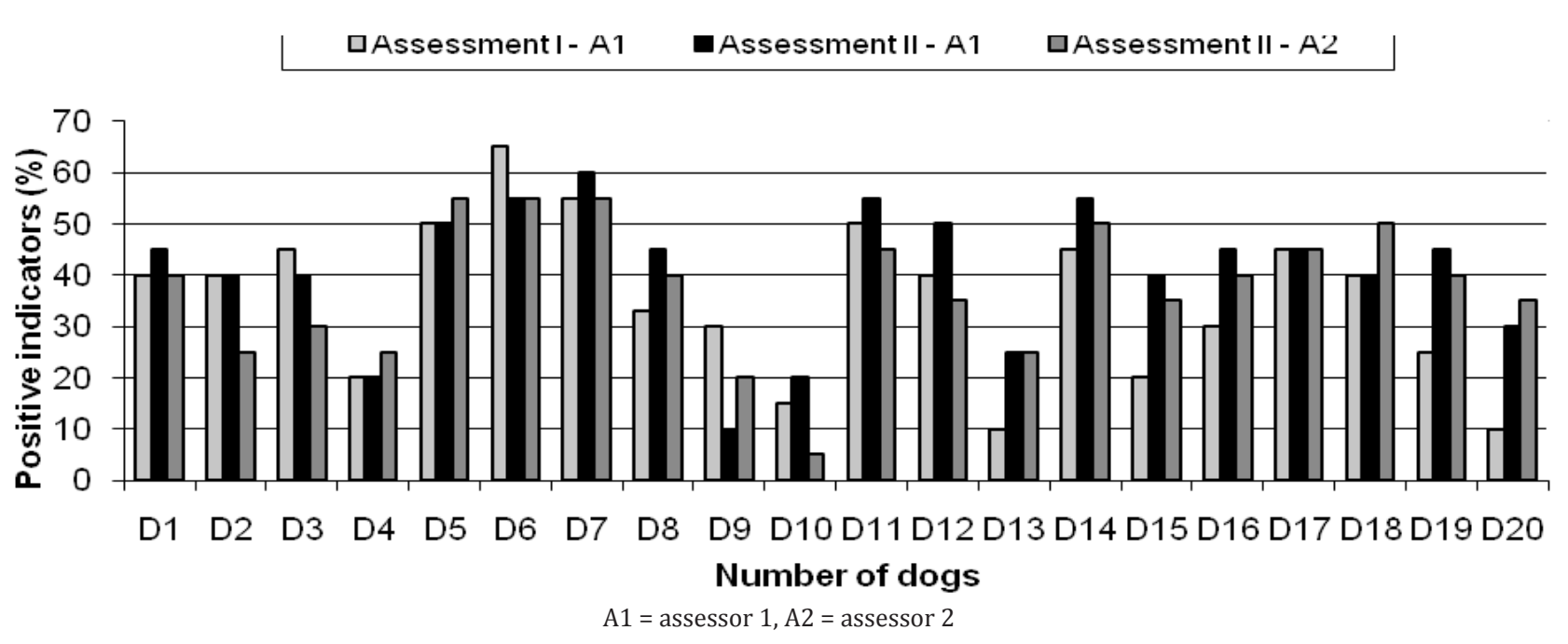

Figure 2. Proportion of positive indicators within the two assessments of the studied dogs

positive effect on the animals (Wells, 2004). This fact is reported also by the personnel of the animal protection associations within the county where our study was performed, and, taking into account the limited resources they administer (these associations functioning based on funds from donations), it could be assumed that it is a national problem. The main concerns of the administrators of the studied shelter regarding the dogs kept there were the lack of the volunteers and the inconstant activity of these within the shelter. This way the permanent personnel, being in low numbers, do not always succeed to perform a satisfying level of socialization with the dogs, the main activities being the cleaning of the shelter, feeding the dogs and veterinary assistance for the animals in need. Thus, even if the caregivers of the association are aware of the importance of socialization, because of the lack of time and resources this is not constantly achieved.

Tuber et al. (1999) show that the grooming sessions of the animals are an adequate way to socialize with the dogs and help reducing the stress level showed by these animals. Petting of the animals was demonstrated too having beneficial effects on both the physiological and behavioral stress responses in dogs (Hennessy et al., 1998). These two activities proved to be beneficial on the studied animals as the results of the second assessment suggested. The continuation of the study could be realised using the same method in other private or public shelters too.
For five dogs, A2 obtained higher LQ scores than $\mathrm{A} 1$ in the final assessment (Figure 1). This aspect is explained by the fact that $A 2$, even if recorded during the assessment a variable percentage of positive indicators, the prevalence of the negative indicators was lower or equal with that obtained by A1 (Figure 2). This result can occur due to the observation of the same negative behavior repeatedly, aspect that is not quantified in the LQ score, only the presence or absence of a given indicator being recorded. This could have been the explanation of the fact that, for some animals, A1 recorded lower percentages of positive indicators during the second assessment comparing with the first one.

In the first assessment the maximum percentage of positive indicators $(65 \%)$ observed was recorded in D6 and the maximum percentage of negative indicators (40\%) in D9 and D20. The minimum percentage of positive indicators $(10 \%)$ was observed in the animals noted as D13 and D20, and the minimum percentage of negative indicators $(0 \%)$ was observed in D16 (Figure 3). The mean percentage of positive indicators after the first assessment was $32.25 \%$, more than half of the dogs (55\%) exceeding this value. The mean percentage of negative indicators was $18.25 \%$, half of the assessed animals (50\%) recording a lower percentage. Kiddie and Collins $(2014 ; 2015)$ obtain a percentage of $2 \%$ negative LQ scores, comparing with the $30 \%$ obtained in the first stage of our study. These results suggest a higher prevalence of behavioral disorders in the dogs assessed in our 
study. The presence of these behavioral disorders could be the cause for which part of the assessed dogs were sheltered for a long period and were not relocated through the adoption programs of the association.

The research papers indicate major differences between the behavior of dogs with owners and stray ones. The main majority of stray animals are taken in public or private shelters. The main aim of the shelters is to facilitate the quickest possible relocation of the animals, but for many of them the shelter becomes their permanent living environment (Barrera et al., 2010). The same authors demonstrate that comparing with the dogs with owners, the dogs in shelters display more frequently fear associated behaviors (tail lowered and ears in ventro-caudal position, low body posture). As regards socialization behavior, both the dogs with owners and those without manifest the intention of socializing with people, but the stray dogs stay more time around the assessor, which could suggest their increased need to interact with humans. Wells and Hepper (2000) report that some behavioral problems complained of by the adopters could be caused by the stressing environment in the shelters, namely fear, hyperreactivity and excessive barking. Aggressiveness is also an important factor that leads to failure in establishing a relationship between the animal and a possible adopter (Serpell and Jagoe, 1995).
Gácsietal.(2001) demonstrate that the animals housed in shelters can develop attachment toward unknown people relatively quickly. Because of this, it was considered that the implementation of an intensive socialization programme could lead to the improvement of the animals' behavior.

The maximum percentage of the positive indicators (60\%) observed by $\mathrm{A} 1$ in the second assessment was recorded in D7, and the maximum percentage of negative indicators (25\%) in the dogs D15 and D20 (Figure 3). The mean percentage of positive indicators obtained by $\mathrm{A} 1$ in the second assessment was higher with 5.5\% than the mean value of the positive indicators obtained in the first assessment. The mean percentage of the negative indicators obtained by A1 was of $12 \%$, more than half $(60 \%)$ of the animals having a lower percentage. Comparing with the mean value of the same indicators in the first assessment performed by A1, a $6.25 \%$ lowering was recorded in the second assessment.

In the assessment performed by $\mathrm{A} 2$ the maximum percentages of the positive indicators (55\%) were recorded in D5, D6 and D7, and the maximum percentage of the negative indicators (30\%) for D20. The minimum percentage of the positive indicators $(5 \%)$ was noted in the animal D10 and the minimum percentage of the negative indicators (0\%) was observed in D8 (Figure 2 and Figure 3).

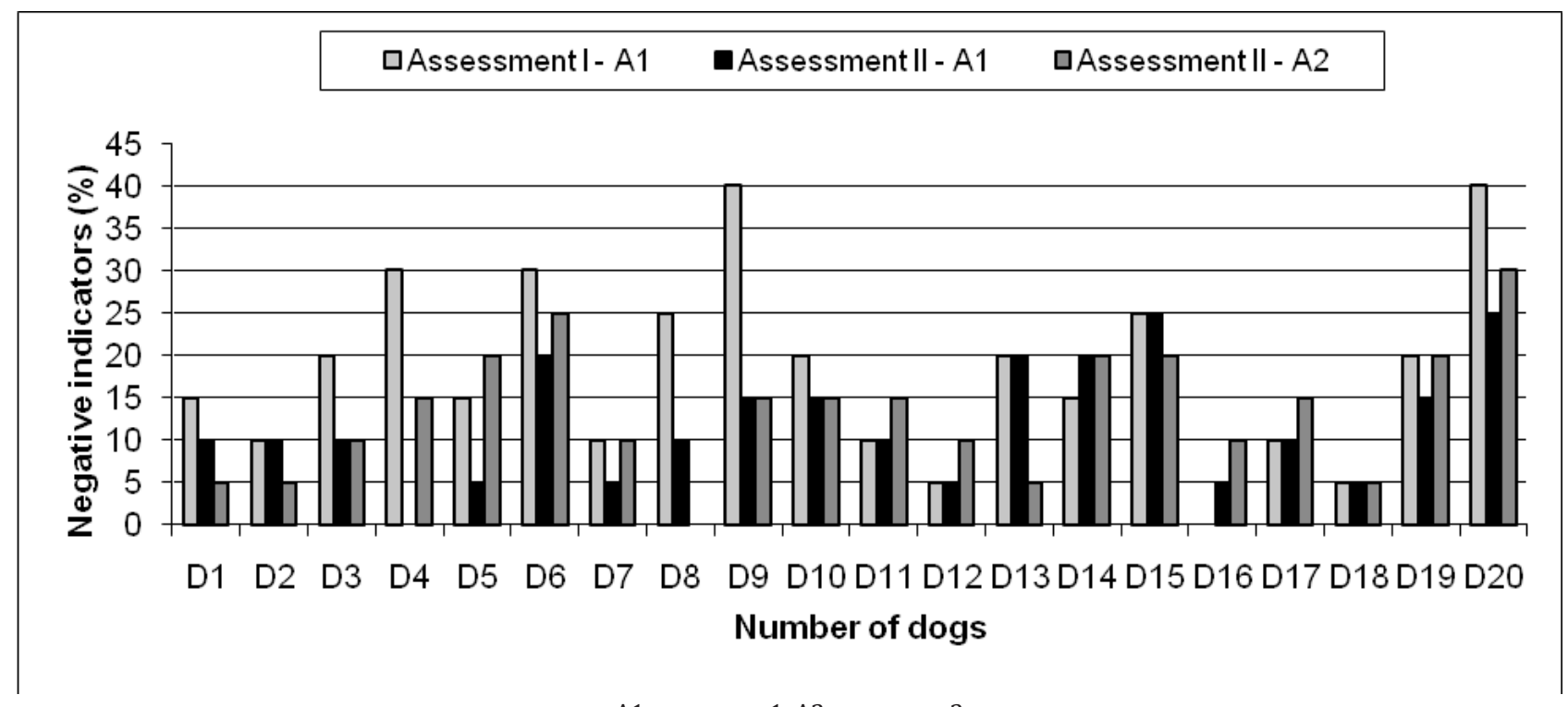

$\mathrm{A} 1=\operatorname{assessor} 1, \mathrm{~A} 2=\operatorname{assessor} 2$

Figure 3. Proportion of negative indicators within the two assessments of the studied dogs 
Table1. The prevalence of negative behavioral indicators and the significance of difference between assessments

\begin{tabular}{|c|c|c|c|c|c|}
\hline \multirow[b]{3}{*}{ Behavioral indicators } & \multicolumn{3}{|c|}{$\%$ of dogs } & \multicolumn{2}{|c|}{$P$ value } \\
\hline & $\mathbf{A 1}$ & & $\mathbf{A 2}$ & \multirow{2}{*}{$\begin{array}{c}\text { A1 } \\
\text { Assessment } \\
\text { I - II }\end{array}$} & \multirow[b]{2}{*}{ A1- A2 } \\
\hline & $\begin{array}{c}\text { Assessment } A \\
\text { I }\end{array}$ & $\begin{array}{l}\text { Assessment } \\
\text { II }\end{array}$ & $\begin{array}{l}\text { Assessment } \\
\text { II }\end{array}$ & & \\
\hline \multicolumn{6}{|c|}{ Unprovoked negative behavior } \\
\hline Repeatedly pacing in the pen & 45 & 20 & 15 & 0.096 & 0.681 \\
\hline Repeatedly jumping on the kennel wall & 5 & 0 & 10 & 0.317 & 0.152 \\
\hline Tail chasing & 0 & 0 & 0 & & 1.000 \\
\hline Circling & 0 & 0 & 0 & & 1.000 \\
\hline Repeatedly display playing position & 5 & 0 & 0 & 0.317 & 1.000 \\
\hline Excessive drinking & 0 & 0 & 5 & 1.000 & 0.317 \\
\hline Panting & 45 & 30 & 40 & 0.333 & 0.513 \\
\hline Apathy & 5 & 0 & 0 & 0.317 & 1.000 \\
\hline Escape attempt & 0 & 0 & 0 & 1.000 & 1.000 \\
\hline Hiding & 10 & 15 & 25 & 0.637 & 0.435 \\
\hline Chewing bars & 0 & 0 & 0 & 1.000 & 1.000 \\
\hline Low posture & 20 & 20 & 25 & 1.000 & 0.708 \\
\hline Coprophagy & 0 & 0 & 0 & 1.000 & 1.000 \\
\hline Lifting a front leg & 0 & 0 & 0 & 1.000 & 1.000 \\
\hline Standing & 65 & 65 & 40 & 1.000 & 0.118 \\
\hline Sniffing a surface/nose on a surface & 10 & 5 & 20 & 0.553 & 0.157 \\
\hline Whining & 5 & 15 & 15 & 0.298 & 1.000 \\
\hline Aggressiveness toward other dogs & 10 & 0 & 0 & 0.152 & 1.000 \\
\hline Startling & 30 & 0 & 0 & 0.009 & 1.000 \\
\hline $\begin{array}{l}\text { Box walking without } \\
\text { exploring environment }\end{array}$ & 10 & 10 & 10 & 1.000 & 1.000 \\
\hline \multicolumn{6}{|c|}{ Provoked negative behavior } \\
\hline Oral behaviors, abnormal movements & 50 & 20 & 30 & 0.050 & 0.471 \\
\hline Ambivalent posture & 45 & 35 & 30 & 0.524 & 0.739 \\
\hline Aggressiveness & 5 & 5 & 5 & 1.000 & 1.000 \\
\hline
\end{tabular}

$\mathrm{P}<0.05$ - the difference is statistically significant 
Table 2. The prevalence of positive behavioral indicators and the significance of difference between assessments

\begin{tabular}{|c|c|c|c|c|c|}
\hline \multirow[b]{3}{*}{ Behavioral indicators } & \multicolumn{3}{|c|}{$\%$ of dogs } & \multicolumn{2}{|c|}{$P$ value } \\
\hline & \multicolumn{2}{|c|}{ A1 } & \multirow{2}{*}{$\begin{array}{c}\text { A2 } \\
\begin{array}{c}\text { Assessment } \\
\text { II }\end{array}\end{array}$} & \multirow{2}{*}{$\begin{array}{c}\text { A1 } \\
\text { Assessment } \\
\text { I - II }\end{array}$} & \multirow[b]{2}{*}{ A1- A2 } \\
\hline & $\begin{array}{l}\text { Assessment } \\
\text { I }\end{array}$ & $\begin{array}{l}\text { Assessment } \\
\text { II }\end{array}$ & & & \\
\hline \multicolumn{6}{|c|}{ Unprovoked positive behavior } \\
\hline High level of activity & 30 & 35 & 30 & 0.739 & 0.739 \\
\hline Grooming & 5 & 10 & 15 & 0.553 & 0.637 \\
\hline Alert & 80 & 95 & 90 & 0.157 & 0.553 \\
\hline Scanning the environment & 95 & 90 & 80 & 0.553 & 0.382 \\
\hline Exploring environment & 25 & 25 & 40 & 1.000 & 0.317 \\
\hline Adopting playing position & 5 & 0 & 10 & 0.317 & 0.152 \\
\hline Ears up & 60 & 50 & 80 & 0.530 & 0.050 \\
\hline High body position & 50 & 65 & 45 & 0.343 & 0.209 \\
\hline $\begin{array}{l}\text { Spending time in the front } \\
\text { part of the box }\end{array}$ & 65 & 65 & 55 & 1.000 & 0.524 \\
\hline Grunting & 15 & 10 & 0 & 0.637 & 0.152 \\
\hline Laying down & 50 & 40 & 35 & 0.435 & 0.747 \\
\hline Playing with objects & 0 & 0 & 10 & 1.000 & 0.152 \\
\hline Playing with other dogs & 30 & 30 & 25 & 1.000 & 0.727 \\
\hline Licking other dogs' face & 0 & 10 & 0 & 0.152 & 0.152 \\
\hline Tail wagging & 60 & 85 & 65 & 0.080 & 1.000 \\
\hline Shaking & 0 & 5 & 5 & 0.317 & 1.000 \\
\hline \multicolumn{6}{|c|}{ Provoked positive behavior } \\
\hline Tail wagging & 65 & 80 & 80 & 0.294 & 1.000 \\
\hline Laying down & 0 & 15 & 15 & 0.075 & 1.000 \\
\hline Initiating physical contact & 65 & 80 & 65 & 0.294 & 0.294 \\
\hline Shaking & 5 & 25 & 5 & 0.080 & 0.080 \\
\hline
\end{tabular}

$\mathrm{P}<0.05$ - the difference is statistically significant

The mean percentage of the positive indicators obtained by A2 in the second assessment was of $37.5 \%$, more than half of the dogs (55\%) exceeding this value (the same percentage than that recorded by A1) (Figure 2). This mean value is lower with
$3.25 \%$ than the mean of the positive indicators obtained by A1 in the second assessment. The mean percentage of the negative indicators recorded by A2 was $13.5 \%$, less than half of the animals (45\%) showed a lower percentage (Figure 3 ). This value 
is $1.5 \%$ higher than the mean value obtained by the $\mathrm{A} 1$ in the second assessment.

Out of the 43 indicators analysed (23 negative and 20 positive), six (tail chasing, circling, escape attempt, chewing bars, coprophagy and lifting a front leg) were not observed in none of the 20 assessed dogs, irrespective the evaluation phase or the assessor (Tables 2 and 3). These indicators were associated in previous studies with high levels of stress or precarious housing conditions (Beerda et al., 1999; Stephen and Ledger, 2005). Moreover, two of these indicators, namely tail chasing and circling are considered stereotypic behavioral disorders (Hecht and Horowitz, 2015). The absence of these in the range of behaviours displayed by the studied animals can suggest the fact that these dogs are housed in such conditions that did not trigger the occurrence of behavioural stereotypes. In addition, the absence of these may imply that the management practices applied in the shelter have a beneficial effect preventing negative behaviors that are documented in the literature being associated with stress.

For the majority of the negative and positive indicators observed in the studied dogs no significant differences were recorded comparing the results obtained by $\mathrm{A} 1$ in the two assessments and by $\mathrm{A} 1$ and $\mathrm{A} 2$ in the second assessment (Tables 1 and 2). For only two negative behavioral indicators (startling and oral behaviors, abnormal movements) the differences were statistically significant $(\mathrm{P}<0.05)$ when the results obtained by A1 were compared between the two assessments.

These indicators were associated in previous research with a high stress levels (Beerda et al., 1998; Hiby et al., 2006). The fact that in our study these indicators have a statistically significant decrease, suggests that the socialization programme had the desired effect. The aim of an intensive socialization programme with the dogs in a shelter should always be the encouragement of the behavioral traits wanted, desired by the adopters, increasing the chances for the dogs to be adopted and also the possibility of the caregivers to work with them as long as they are kept in the shelter (Moesta et al., 2015).

\section{Conclusion}

The higher QL scores obtained after the enrichment programme are proof that such a pro- gramme has positive effects on the behavior and on the quality of life of shelter dogs.

The hereby study represents the first attempt in this field, in our country. Carrying these researches on is justified from a national and international scientific reporting stand point, as well as for finding some practical methods of solving the stray dogs' problem in Romania, taking into account the veterinarian and humanitarian professional ethics and the wellbeing of these animals which depend on us.

Acknowledgments. This research did not receive any specific grant from funding agencies in the public, commercial, or not-for-profit sectors.

\section{References}

1. Barrera G, Jakovcevic A, Bentosela M (2008). Calidad de vida de perros alojados en refugios: intervenciones para mejorar su bienestar. Suma Psicológica, 15: 337-354.

2. Barrera G, Jakovcevic A, Elgier AM, Mustaca A, Bentosela M (2010). Responses of shelter and pet dogs to an unknown human. Journal of Veterinary Behavior, 5: 339-344.

3. Beerda B, Schilder MBH, Van Hooff JARAM, Vries HW, Mol JA (1998). Behavioural, saliva cortisol and heart rate responses to different types of stimuli in dogs. Applied Animal Behaviour Science, 58: 365-381.

4. Beerda B, Schilder MBH, Van Hooff JARAM, Vries HW, Mol JA (1999). Chronic stress in dogs subjected to social and spatial restriction: behavioral responses. Physiology \& Behavior, 66: 233-242.

5. De Palma C, Viggiano E, Barillari E, Palme R, Dufour AB, Fantini C, Natoli E (2005). Evaluating the temperament in shelter dogs. Behavior, 142: 1307-1328.

6. Gácsi M, Topal J, Miklosi A, Doka A, Csanyi V (2001). Attachment behavior of adult dogs (Canis familiaris) living at rescue centers: Forming new bonds. Journal of Comparative Psychology, 115: 423-431.

7. Hecht J, Horowitz A (2015). Introduction to dog behavior. In: Animal behavior for shelter veterinarians and staff (pp. 5-24). John Wiley \& Sons, Ames.

8. Hennessy MB, Williams M, Mellott C, Douglas C (1997). Plasma cortisol levels of dogs at a county animal shelter. Physiology \& Behavior, 62: 485-490.

9. Hennessy MB, Williams MT, Miller DD, Douglas CW, Voith VL (1998). Influence of male and female petters on plasma cortisol and behaviour: can human interaction reduce the stress of dogs in a public animal shelter. Applied Animal Behaviour Science, 61: 63-77.

10. Hiby EF, Rooney NJ, Bradshaw JWS (2006). Behavioural and physiological responses of dogs entering re-homing kennels. Physiology \& Behavior, 89: 385-391.

11. Kiddie JL, Collins LM (2014). Development and validation of a quality of life assessment tool for use in kennelled dogs (Canis familiaris). Applied Animal Behaviour Science, 158: 457-468. 
12. Kiddie JL, Collins LM (2015). Identifying environmental and management factors that may be associated with the quality of life of kennelled dogs (Canis familiaris). Applied Animal Behaviour Science, 167: 43-55.

13. Moesta A, McCune S, Deacon L, Kruger KA (2015). Canine enrichment. In: Animal Behavior for Shelter Veterinarians and Staff (pp. 160-170). John Wiley \& Sons, Ames.

14. Normando S, Corain L, Salvadoretti M, Meers L, Valsecchi $P$ (2009). Effects of an enhanced human interaction program on shelter dogs' behavior analysed using a novel nonparametric test. Applied Animal Behaviour Science, 116: 211-219.

15. Serpell J, Jagoe JA (1995). Early experience and the development of behavior. In: The domestic dog: its evolution, behaviour and interactions (pp. 79-102). Cambridge University Press, Cambridge.
16. Stephen JM, Ledger RA (2005). An audit of behavioral indicators of poor welfare in kenneled dogs in the United Kingdom. Journal of Applied Animal Welfare Science, 8: 79-95.

17. Tuber D, Miller D, Caris K, Halter R., Linden F., Hennessy M (1999). Dogs in animal shelters: problems, suggestions and needed expertise. Psychological Science, 10: 379-386.

18. Wells DL, Hepper PG (2000). The influence of environmental change on the behaviour of sheltered dogs. Applied Animal Behaviour Science, 68: 151-162.

19. Wells DL, Graham L, Hepper PG (2002). The influence of length of time in a rescue shelter on the behaviour of kennelled dogs. Animal Welfare, 11: 317-325.

20. Wells DL (2004). A review of environmental enrichment for kennelled dogs, Canis familiaris. Applied Animal Behaviour Science, 85: 307-317. 